\title{
Eat well to get well
}

\section{E F M Wouters}

\section{Nutrition and energy supply are important components of rehabilitation programmes for patients with COPD.}

1

mprovement in functional performance is considered an important management goal in patients with chronic obstructive pulmonary disease (COPD) Pulmonary rehabilitation is now considered as an evidence based intervention to achieve an improvement in functional capacity as well as other management goals such as improved health status and reduction in breathlessness. ${ }^{1}$ Although exercise training is considered the core component of every pulmonary rehabilitation programme, the optimal method of exercise training as well as the optimal training intensity remains a matter of debate. Standard recommendations for exercise training in healthy subjects are generally transferred to disabled patients with COPD, and the complexity of the disease related changes which make an important contribution to the functional disability experienced is usually ignored.

The metabolic demand of exercise, reflected in the energy expended on activities, is generally overlooked when patients are stressed to increase their activity level. Consideration of energy balance in COPD is important because weight loss and, specifically loss in fat mass, is the result of a negative energy balance. During the last decade most attention has been focused on resting energy expenditure in patients with COPD; in many of these patients hypermetabolism can be demonstrated which is partly related to the level of systemic inflammation. ${ }^{2}{ }^{3}$ However, in normal subjects the energy expenditure for activities is the most variable component of total energy expenditure. While studies in other chronic wasting diseases characterised by hypermetabolism and systemic inflammation-for example, cancer, chronic heart failure, AIDShave shown an adaptive decrease in activity induced energy expenditure so that total daily energy expenditure is normal, increased activity induced and total daily energy expenditure has been measured in free living ambulatory COPD patients. ${ }^{4}$ Great variations in total energy expenditure, physical activity, and energy intake have been reported in underweight patients with COPD living at home.

One obvious way of improving energy balance is to decrease energy expenditure. However, restricting energy output is not desirable as maintaining an active lifestyle is one of the management objectives in patients with COPD. This implies that patients with COPD who suffer from weight loss - and even some patients with a stable weight-should be encouraged to increase their apparently normal energy intake. The results presented by Steiner et al in this issue of Thorax outline the importance of energy balance in COPD patients advised to increase exercise. ${ }^{6}$ Patients participating in a rehabilitation programme who received a $570 \mathrm{kcal}$ carbohydrate rich supplement gained weight, principally due to changes in fat mass, while those in the placebo group lost weight; these differences were even greater in patients with a body mass index (BMI) of $>19 \mathrm{~kg} / \mathrm{m}^{2}$, which suggests that, even under conditions of metabolic stress such as exercise, disturbances in energy balance can be introduced in this group of patients. The weight loss in the placebo group indicates the importance of asking patients for involuntary weight loss as an indicator of energy imbalance, either to increased energy expenditure or relatively decreased energy intake, and stresses the need to monitor body weight or body composition, especially during rehabilitation programmes. Recent epidemiological data underscore the clinical relevance of this observation.

Assuming that the long term aim of rehabilitation is the maintenance of physical fitness through a more active lifestyle, the implications of the findings of Steiner et al could be that this change in lifestyle can be complicated by a persistent negative energy balance contributing to progressive weight loss. A recent study by Goris et $a l^{8}$ supports this hypothesis. They studied the energy balance of depleted ambulatory COPD patients in relation to their habitual level of physical activity and consumption of oral nutritional supplements and found that the mean change in body mass over a period of 3 months was negatively related to the mean level of physical activity, indicating that knowledge of the individual physical activity is necessary for estimating the energy needs of the COPD patient. However, it has to be realised that supplementation of high carbohydrate diets, as in the study of Steiner $e t$ $a l$, is the complete opposite for most people for whom trying to eat less and avoiding calorie-dense foods is the norm. The dietary advice for weight stable COPD patients is generally to eat a healthy diet, which is usually interpreted as a diet according to general dietary recommendations-that is, low in fat, high in fibre, containing complex carbohydrates and including large quantities of fruit and vegetables. Behaviour changes away from a habitual pattern and in a direction opposite to the social norm are difficult to establish. It is therefore very important that caregivers and heath professionals provide a consistent message on diet and nutrition and that they increase social support, pay attention to the patient's nutritional status, and provide adequate dietary advice if weight loss is observed. ${ }^{9}$

Generally considered as an energy storage, interesting data have recently been reported regarding the regulatory role of fat mass in body weight homeostasis by production of leptin. This hormone not only has an intriguing role in body weight homeostasis, but also plays a protective role in severe stress states and is involved in respiratory regulation. ${ }^{10}{ }^{11}$ Circulating leptin concentrations are proportional to the amount of fat mass; in stable depleted patients with COPD, dietary intake-as well as weight gain after nutritional therapyare inversely related to plasma leptin levels. ${ }^{12}{ }^{13}$ It would be interesting to integrate leptin metabolism into future nutritional intervention studies.

In a subgroup of patients with BMI $>19 \mathrm{~kg} / \mathrm{m}^{2}$, Steiner et al found a significantly greater increase in incremental shuttle walk distance after carbohydrate supplementation than in those receiving placebo treatment. Indeed, carbohydrates are an important source of energy for endurance. However, in addition to fuel supply, the adaptations of the metabolic machinery in the skeletal muscle tissue of COPD patients have to be taken into account. Patients with COPD have reduced oxidative capacity which is closely related to the reduction in type I fibres. ${ }^{14}$ Exercise training clearly contributes to an improvement in the aerobic enzyme capacity of patients with COPD. ${ }^{15}$ It would be intriguing to relate this reported functional improvement after carbohydrate supplementation to the metabolic enzyme content of the lower limb muscles. Although a BMI of $19 \mathrm{~kg} / \mathrm{m}^{2}$ could be considered an acceptable lower limit of normal, the optimal BMI in patients with COPD is still open to question. Survival data showed a worse prognosis in COPD patients with a BMI of $<21 \mathrm{~kg} / \mathrm{m}^{2}$; a BMI of $>19 \mathrm{~kg} / \mathrm{m}^{2}$ could not therefore be considered as an acceptable lower limit in these patients. ${ }^{16}{ }^{17}$

The discrepancy between the definition of malnutrition based on BMI and 
an unintentional weight loss was recently demonstrated in a screening of nutritional status in a large study of hospitalised patients: $19 \%$ of the patients with weight loss $>10 \%$ during the past 6 months still had a BMI of $>25 \mathrm{~kg} / \mathrm{m}^{2}$. The authors conclude that unintentional weight loss is a better indicator of disease related malnutrition since unintentional weight loss reflects insufficient energy and nutrient availability or increased needs. ${ }^{18}$

Body compositional studies in COPD have clearly shown that weight loss is generally accompanied by a loss in fat free mass but that muscle wasting may also occur in stable subjects of normal weight. It is specifically the loss in fat free mass or other measures of muscle mass that are related to impaired skeletal muscle strength and exercise capacity. ${ }^{19}{ }^{20}$ This wasting of muscle mass is due to an impaired balance between protein synthesis and protein breakdown. Besides nutritional abnormalities and physical inactivity, altered neuroendocrine response and the presence of a systemic inflammatory response may contribute to a negative protein balance in chronic diseases. This disproportionate muscle wasting linked to systemic inflammation is commonly referred to as the cachexia syndrome; processes that govern the maintenance of skeletal muscle and muscle plasticity such as skeletal muscle degeneration, apoptosis, and regeneration must also be considered in order to modify the muscle compartment in patients suffering from chronic inflammatory conditions. From a therapeutic perspective, it is important to analyse the relative contribution of each of these factors to altered protein synthesis and protein breakdown, respectively. Uncontrolled protein breakdown cannot be overcome simply by increasing protein synthesis. Furthermore, consistently reduced plasma levels of branched chain amino acids (BCAAs) have been reported in underweight COPD patients and in those with low muscle mass. ${ }^{21}{ }^{22}$ These BCAAs are important precursors of glutamate which is one of the most important non-essential amino acids in muscle. A consistently reduced muscle glutamate level in patients with severe COPD was found to be further decreased during submaximal exercise. ${ }^{23}$ These metabolic changes illustrate the complexity of nutritional intervention strategies to gain muscle mass in depleted COPD patients. A recent study by Creutzberg et al ${ }^{24}$ demonstrates the possibility of achieving these treatment goals.
Nutritional supplementation therapy, implemented on energy expenditure assessment as part of a pulmonary rehabilitation programme, was found to be effective in increasing body weight and muscle mass and these effects resulted in an improvement in muscle performance in these patients. ${ }^{24}$ The same authors had previously reported that non-response to nutritional therapy in patients with COPD is associated with ageing, relative anorexia, and an increased systemic inflammatory response. ${ }^{25}$

The data reported by Steiner et al in this issue of Thorax show that nutrition and energy supply, although intuitively acknowledged, are important components of a multidisciplinary rehabilitation programme. Future studies of nutritional and metabolic regulation in the management of COPD must include an understanding of the complexity of the metabolic and structural adaptations as part of the multicomponent pathology of this condition.

\section{Thorax 2003;58:739-740}

\section{Author's affiliation}

E F M Wouters, Department of Respiratory Medicine, University Hospital Maastricht, PO Box 5800, 6202 AZ Maastricht, The

Netherlands; ewo@slon.azm.n

\section{REFERENCES}

1 Pauwels RA, Buist AS, Calverley PM, et al. Global strategy for the diagnosis, management, and prevention of chronic obstructive pulmonary disease. NHLBI/WHO Global Initiative for Chronic Obstructive Lung Disease (GOLD) Workshop summary. Am J Respir Crit Care Med 2001;163:1256-76.

2 Creutzberg EC, Schols AM, Bothmer Quaedvlieg FC, et al. Prevalence of an elevated resting energy expenditure in patients with chronic obstructive pulmonary disease in relation to body composition and lung function. Eur J Clin Nutr 1998;52:396-401

3 Nguyen LT, Bedu M, Caillaud D, et al. Increased resting energy expenditure is related to plasma TNF-alpha concentration in stable COPD patients. Clin Nutr 1999; 18:269-74.

4 Baarends EM, Schols AM, Pannemans DL, et al. Total free living energy expenditure in patients with severe chronic obstructive pulmonary disease. Am J Respir Crit Care Med 1997; 155:549-54.

5 Slinde F, Ellegard L, Grönberg AM, et al. Total energy expenditure in underweight patients with severe chronic obstructive pulmonary disease living at home. Clin Nutr 2003;22:159-65.

6 Steiner MC, Barton RL, Singh SJ, et al. Nutritional enhancement of exercise performance in chronic obstructive pulmonary disease: a randomised controlled trial. Thorax 2003;58:745-51

7 Prescott E, Almdal T, Mikkelsen KL, et al. Prognostic value of weight change in chronic obstructive pulmonary disease: results from the Copenhagen City Heart Study. Eur Respir J 2002;20:539-44.
8 Goris AHC, Vermeeren MAP, Wouters EFM, et al. Energy balance in depleted ambulatory patients with chronic obstructive pulmonary disease: the effect of physical activity and oral nutritional supplementation. Br J Nutr 2003:89:725-9

9 Schols AMWJ, Brug J. Efficacy of nutritional intervention in chronic obstructive pulmonary disease. Eur Respir Monogr 2003;8 (Monograph 24): 142-52

10 Lord GM, Matarese G, Howard LK, et al. Leptin modulates the T-cell immune response and reverses starvation-induced immunosuppression. Nature 1998;394:897-901

11 O'Donnell CP, Schaub CD, Haines AS, et al. Leptin prevents respiratory depression in obesity. Am J Respir Crit Care Med 1999; 159: 1477-84.

12 Takabataka N, Nakamura H, Abe S, et al Circulating leptin in patients with chronic obstructive pulmonary disease. Am J Respir Crit Care Med 1999;159:1215-9.

13 Schols AMWJ, Creutzberg EC, Buurman WA, et al. Plasma leptin is related to proinflammatory status and dietary intake in patients with chronic obstructive pulmonary disease. Am J Respir Crit Care Med 1999:160:1220-6.

14 Gosker HR, van Mameren H, van Dijk PJ, et al. Skeletal muscle fibre-type shifting and metabolic profile in patients with chronic obstructive pulmonary disease. Eur Respir J 2002; 19:617-26.

15 Maltais F, Simard AA, Simard C, et al. Oxidative capacity of the skeletal muscle and lactic acid kinetics during exercise in normal subjects and in patients with COPD. Am J Respir Crit Care Med 1996;153:288-93.

16 Schols AM, Slangen J, Volovics L, et al. Weight loss is a reversible factor in the prognosis of chronic obstructive pulmonary disease. Am J Respir Crit Care Med 1998;157:1791-7

17 Landbo C, Prescott E, Lange $P$, et al. Prognostic value of nutritional status in chronic obstructive pulmonary disease. Am J Respir Crit Care Med 1999;160:1856-61

18 Kruizenga HM, Wierdsma NJ, Van Bokhorst $M A E$, et al. Screening of nutritional status in The Netherlands. Clin Nutr 2003;22: 147-52.

19 Bernard S, Leblanc P, Whittom F, et al. Peripheral muscle weakness in patients with chronic obstructive pulmonary disease. Am J Respir Crit Care Med 1998;158:629-34.

20 Baarends EM, Schols AM, Mostert R, et al. Peak exercise response in relation to tissue depletion in patients with chronic obstructive pulmonary disease. Eur Respir $\rfloor$ 1997; 10:2807-13.

21 Yoneda T, Yoshikawa M, Fu A, et al. Plasma levels of amino acids and hypermetabolism in patients with chronic obstructive pulmonary disease. Nutrition 2001;17:95-9.

22 Engelen MP, Wouters EF, Deutz NE, et al. Factors contributing to alterations in skeletal muscle and plasma amino acid profiles in patients with chronic obstructive pulmonary
disease. Am J Clin Nutr 2000;72:1480-7.

23 Engelen MPKJ, Wouters EFM, Deutz NEP, et al. Effects of exercise on amino acid metabolism in patients with chronic obstructive pulmonary disease. Am J Respir Crit Care Med 2001;163:859-64.

24 Creutzberg EC, Wouters EFM, Mostert R, et al. Efficacy of nutritional supplementation therapy in depleted patients with chronic obstructive pulmonary disease. Nutrition 2003; 19:120-7

25 Creutzberg EC, Schols AMWJ, Weling-Scheepers CAPM, et al. Characterization of nonresponse to high caloric oral nutritional therapy in depleted patients with chronic obstructive pulmonary disease. Am J Respir Crit Care Med 2000;161:745-52. 
findings in the study by Spruit et al is that preadmission steroid exposure (or factors giving rise to a need for courses of Peripheral muscle weakness in
COPD: where does it come from? M I Polkey

Do patients with frequent exacerbations of COPD have a more rapid rate of decline in quadriceps strength than those with stable disease?

$\mathrm{E}$ xertional dyspnoea is usually the main complaint of a patient with chronic obstructive pulmonary disease (COPD). Although this is partly a result of impaired pulmonary mechanics, exercise performance remains substantially reduced even if both lungs are replaced, ${ }^{1}$ which suggests that the lungs alone cannot explain exertional dyspnoea. Quadriceps myopathy is a feature of COPD. Histological examination of quadriceps biopsy tissues shows a switch towards fatiguable type II fibres ${ }^{2}$ and reduced oxidative enzymes. This in turn leads to anaerobic metabolism at lower work rates than in normal subjects. ${ }^{3}$ Lactic acid, generated as a byproduct of anaerobic metabolism, is buffered by bicarbonate with the generation of carbon dioxide. Patients with severe COPD cannot clear carbon dioxide by increasing their ventilation and thus treadmill walking may result in transient hypercapnia and acidosis. ${ }^{4}$ It is perhaps not surprising therefore that quadriceps weakness is demonstrably related to the utilisation of healthcare resources. $^{5}$

The magnitude of quadriceps weakness is related to disease severity, ${ }^{6}$ but there is wide variation for a given forced expiratory volume in 1 second $\left(\mathrm{FEV}_{1}\right)$ and a number of competing (though not mutually exclusive) theories have been proposed as contributors to quadriceps muscle weakness in COPD. The most straightforward suggestion is that the muscle changes are simply a local result of inactivity. This explanation is favoured by the preferential involvement of lower limb muscle (generally less active in COPD) over upper limb muscle, ${ }^{67}$ as well as the sparing of the diaphragm ${ }^{8}$ which, of course, shows increased activity. This argument is further supported by the observation that exercise training, ${ }^{9}$ and possibly externally applied nerve stimulation, ${ }^{10}$ can reverse disease induced changes in the muscle. Another explanation is that muscle wasting is the result of a systemic inflammatory response; this hypothesis is supported by data which show that patients who fail to gain weight during a refeeding programme have high levels of soluble tumour necrosis factor (TNF) receptor $55 .{ }^{11}$ In addition, skeletal muscle mass in COPD is inversely related to circulating levels of interleukin (IL)- 6 and TNF- $\alpha .{ }^{12}$

Against this background, Spruit et al ${ }^{13}$ present new data which raise a new hypothesis-that recurrent exacerbations result in stepwise impairment of muscle function. They studied 34 men with moderately severe COPD admitted from an emergency department and measured indices of respiratory and peripheral muscle strength. Systemic levels of insulin-like growth factor I (IGF-I), TNF- $\alpha$, and IL-6, IL-8 (the latter now known as CXCL8), and IL-10 were measured. Control data were obtained from men with stable COPD attending an outpatient clinic and from healthy elderly men. CXCL8 was highest in men admitted to hospital and statistically higher than for stable COPD patients. A similar trend was observed for IL-6, although this was not statistically significant. TNF- $\alpha$ levels were undetectable in all but two of the patients studied. Quadriceps strength was inversely correlated with levels of both CXCL8 and IL-6, as well as with indices of disease severity. Handgrip force correlated weakly with CXCL8 only in the patients admitted to hospital. Follow up data are also provided, although their interpretation is tempered by the fact that nine of the 34 patients dropped out between the first assessment (day 3) and the second assessment (day 8 ), and that a further 12 patients dropped out before the third assessment (day 90), leaving an available pool of just 13 of 34 subjects (38\%). Quadriceps strength was observed to fall by $5 \%$ at day 8 but to have been regained by day 90 .

An important claim of the present study is that quadriceps strength was negatively correlated with CXCL8 on day 3 of admission. Proximal myopathy is a well known consequence of corticosteroid therapy ${ }^{14}$ and the Leuven group have stressed the importance of steroid myopathy in COPD. ${ }^{15}$ In fact, approximately $50 \%$ of the variation in quadriceps strength in patients admitted with COPD can be related to cumulative steroid dose, ${ }^{16}$ and one explanation of the steroids) both increased CXCL8 and reduced quadriceps strength.

Another exciting result is the demonstration that there is an acute loss of muscle force during an acute exacerbation of COPD. As with chronic muscle weakness, various pathophysiological mechanisms could be advanced to explain this. The authors correctly argue that steroids given during the admission are unlikely candidates because the magnitude of force loss is unrelated to steroid dosage, so it may be helpful to consider the physiological site of the weakness. Spruit et al used volitional tests of muscle strength so their results depend both on the contractile properties of the muscles studied and also on the maximality of the effort made during the test. In a study of the unaffected leg of patients admitted with acute hemiplegic stroke-that is, ipsilateral to the lesion-Harris et al ${ }^{17}$ used both nonvolitional and volitional techniques to measure quadriceps strength. With the non-volitional technique she found a significant $(16 \%)$ loss of strength in the first week after admission but a much greater loss $(30 \%)$ when the patients were assessed using a volitional technique, suggesting that volitional techniques may overestimate weakness in acutely ill patients. Preliminary data from a small number of subjects suggest that motor cortex function may be altered (in fact to reduce intracortical inhibition) during acute exacerbations of COPD, ${ }^{18}$ and the present data should be confirmed using a non-volitional technique. The other possibility, which is consistent with the known histological myopathy in stable patients with COPD, is that the weakness is due to an acute myopathy. If so, the contractile properties of the muscle could have been directly impaired by inactivity, ${ }^{17}$ but the acute inflammatory response recognised to accompany acute exacerbations ${ }^{20}$ may also be relevant if an acute exacerbation could be shown to result in local skeletal muscle damage. Myopathy is known to contribute to neurological abnormalities in patients in critical care units ${ }^{21}$; a similar finding in acute exacerbations of COPD would be plausible

It is now recognised that patients with frequent exacerbations of COPD have a more rapid rate of decline in lung function, ${ }^{22}$ and the study by Spruit et al raises the intriguing hypothesis that frequent exacerbators might have a more rapid decline in quadriceps strength. In future, therapeutic strategies aimed at reducing exacerbations (or their effects) might be valuable for maintaining exercise performance in patients with COPD.

Thorax 2003;58:741-742

Therax $2003,58: 741-742$ 


\section{Author's affiliation \\ M I Polkey, Department of Respiratory Medicine, Royal Brompton Hospital and National Heart \& Lung Institute, London SW3 6NP, UK; m.polkey@rbh.nthames.nhs.uk \\ REFERENCES \\ 1 Williams TJ, Patterson GA, McClean PA, et al. Maximal exercise testing in single and double lung transplant recipients. Am Rev Respir Dis 1992;145:101-5. \\ 2 Jakobsson P, Jorfeldt L, Brundin A. Skeletal muscle metabolites and fibre types in patients with advanced chronic obstructive pulmonary disease, with and without chronic respiratory failure. Eur Respir J 1990;3:192-6. \\ 3 Maltais F, Simard AA, Simard C, et al. Oxidative capacity of the skeletal muscle and lactic acid kinetics during exercise in normal subjects and in patients with COPD. Am J Respir Crit Care Med 1996;153:288-93. \\ 4 Polkey MI, Hawkins P, Kyroussis D, et al. Inspiratory pressure support prolongs exercise induced lactataemia in severe COPD. Thorax 2000:55:547-9. \\ 5 Decramer M, Gosselink R, Troosters T, et al. Muscle weakness is related to utilization of health care resources in COPD patients. Eur Respir J 1997:10:417-23. \\ 6 Bernard S, LeBlanc P, Whittom F, et al. Peripheral muscle weakness in patients with chronic obstructive pulmonary disease. $A m$ J Respir Crit Care Med 1998;158:629-34. \\ 7 Man WDC, Soliman MGG, Nikoletou D, et al. Non-volitional assessment of skeletal}

muscle strength in patients with chronic obstructive pulmonary disease. Thorax 2003;58:665-9

8 Polkey MI, Kyroussis D, Hamnegard C-H, et al. Diaphragm strength in chronic obstructive pulmonary disease. Am I Respir Crit Care Med 1996;154:1310-7.

9 Maltais F, LeBlanc P, Simard C, et al. Skeletal muscle adaptation to endurance training in patients with chronic obstructive pulmonary disease. Am J Respir Crit Care Med 1996: 154:442-7.

10 Neder JA, Sword D, Ward SA, et al. Home based neuromuscular electrical stimulation a a new rehabilitative strategy for severely disabled patients with chronic obstructive pulmonary disease (COPD). Thorax 2002:57:333-7.

11 Creutzberg EC, Schols AM, Weling-Scheepers CA, et al. Characterization of nonresponse to high caloric oral nutritional therapy in depleted patients with chronic obstructive pulmonary disease. Am J Respir Crit Care Med 2000;161:745-52.

12 Eid AA, lonescu AA, Nixon LS, et al. Inflammatory response and body composition in chronic obstructive pulmonary disease. Am J Respir Crit Care Med 2001;164: 1414-8.

13 Spruit MA, Gosselink R, Troosters T, et al. Muscle force during an acute exacerbation in hospitalised COPD patients and its relationship with CXCL8 and IGF-1. Thorax 2003;58:752-6.

14 Bowyer S, LaMothe M, Hollister J. Steroid myopathy: incidence and detection in a population with asthma. J Allergy Clin Immunol 1985;76:234-42.
15 Decramer M, de Bock V, Dom R. Functional and histologic picture of steroid-induced myopathy in chronic obstructive pulmonary disease. Am J Respir Crit Care Med 1996;153:1958-64.

16 Decramer M, Lacquet LM, Fagard R, et al. Corticosteroids contribute to muscle weakness in chronic airflow obstruction. Am J Respir Crit Care Med 1994;150:11-6.

17 Harris ML, Polkey MI, Bath PM, et al. Quadriceps muscle weakness following acute hemiplegic stroke. Clin Rehabil $2001 ; 15: 274-81$.

18 Oliviero A, Corbo G, Tonali PA, et al. Functional involvement of central nervous system in acute exacerbation of chronic obstructive pulmonary disease. A preliminary transcranial magnetic stimulation study. $J$ Neurol 2002;249:1232-6.

19 Rutherford OM, Jones DA, Round JM. Long-lasting unilateral muscle wasting and weakness following injury and immobilisation. Scand J Rehabil Med 1990;22:33-7.

20 Dentener MA, Creutzberg EC, Schols AM, et al. Systemic anti-inflammatory mediators in COPD: increase in soluble interleukin 1 receptor II during treatment of exacerbations. Thorax 2001;56:721-6.

21 Rich MM, Teener JWT, Raps EC, et al. Muscle is electrically inexcitable in acute quadriplegic myopathy. Neurology 1996;46:731-6.

22 Donaldson GC, Seemungal TA, Bhowmik A, et al. Relationship between exacerbation frequency and lung function decline in chronic obstructive pulmonary disease. Thorax 2002;57:847-52

\section{Measurement of lung function in preschool children using the interrupter technique}

\section{P D Sly, E Lombardi}

The measurement of airway resistance using the interrupter technique shows considerable promise for assessing lung function in children of preschool age. However, proper attention must be paid to the assumptions that underlie the technique, and appropriate consideration of the effect of the measurement conditions on these assumptions is important for producing reliable data.

M easurement of lung function forms an important part of the clinical assessment and management of older children and adults with lung diseases. Our knowledge about the normal pattern of growth and development of the lungs and the effects of aging comes largely from measuring pulmonary function. While these measurements form a routine part of the life of most clinicians, there has been an age limit below which such information has not been available. Measurement of lung function in preschool children has recently generated much interest with the publication of a number of studies reporting the use of various techniques. ${ }^{1-6}$ Lung function can be difficult to measure in preschool children and is prone to an increased failure rate and increased variability. Two recent papers published in Thorax $^{56}$ describing measurements of airway resistance using the interrupter technique (Rint) deal with the important issue of repeatability of the measurement and variability over time. These issues must be addressed before measurements of Rint can be recommended for routine clinical use in children of preschool age.

\section{PRINCIPLES OF THE INTERRUPTER} TECHNIQUE

The interrupter technique is not new; it was first described by Neergard and Wirz ${ }^{7}$ in 1927 and was used widely in the 1940s and $1950 \mathrm{~s}^{8-10}$ before being largely discarded because it was not clear exactly what it was measuring. The advent of modern computers has allowed a thorough examination of the interrupter technique and an understanding of the physiology underlying the measurements. ${ }^{11-16}$ The basic assumption underlying the interrupter technique is that, following an instantaneous interruption of airflow at the airway opening (by closing a valve or shutter), there is an instantaneous equilibration of pressure between the alveoli and the airway opening (behind the occlusion). The technique further assumes that there is a single value of alveolar pressure. Following the occlusion, a rapid change in pressure is seen which is equal to the Newtonian (that is, frictional) fall in pressure between the alveoli and the airway opening. Dividing this pressure change by the flow occurring immediately before the occlusion allows the calculation of resistance (R)that is, $\mathrm{R}=$ pressure/flow. The initial rapid pressure change is followed by a second slower change in pressure which is related to the viscoelastic properties of the respiratory tissues, together with any gas redistribution that occurs between lung units following the occlusion. The direction of these pressure changes depends on the phase of respiration, 
with occlusions made during inspiration (or at end inspiration) being followed by falls in airway opening pressure, and occlusions made during expiration being followed by increases in airway opening pressure.

\section{LIMITATIONS OF THE INTERRUPTER TECHNIQUE}

There are, however, several problems with the assumptions underlying the interrupter technique that have practical consequences for its use in humans.

(1) An instantaneous occlusion is physically unrealisable and any valve or shutter takes a finite time to close. During this time some gas will continue to pass through the valve and the lung volume (and thus alveolar pressure) will continue to change. These effects have been examined in detail ${ }^{15}$ and were found to be of little clinical importance provided the valve closes within 10 $20 \mathrm{~ms}$.

(2) There is not instantaneous equilibration of alveolar and airway opening pressure following occlusion. The equilibration time is affected by the resistance of the airways and the time constant of pressure transmission. These effects are small in normal lungs, but become increasingly important in the presence of increased resistance and ventilation inhomogeneity. This effect can systematically bias against the use of the interrupter technique for challenge tests such as methacholine challenge.

(3) The presence of a compliant compartment between the resistive airways and the airway opening may buffer the initial rapid "resistive" pressure change, making the calculation of resistance less accurate. These effects are real and potentially clinically important in patients with markedly increased airway resistance or during challenge tests where the airway resistance is deliberately increased. The major compliant pathway in preschool children is the cheeks and upper (extrathoracic) airway, and measurements are routinely made with the subject's cheeks supported in an attempt to minimise this problem.

(4) There is not a single value of alveolar pressure and thus not a single value of airway resistance. While this may seem like a fatal flaw, careful animal studies in which alveolar pressure was measured directly using alveolar capsules $^{12} 13$ showed that the value of resistance calculated from the airway opening pressure represented an "average" resistance and was thus of potential clinical value.

(5) The interrupter resistance has been shown to measure more than the fall in resistive pressure across the airways, and includes all Newtonian resistance from the respiratory system including components from the pulmonary tissues and chest wall, both of which are expected to change under various circumstances likely to be encountered during clinical measurements. Pulmonary tissue resistance increases with increasing lung volumethe opposite to the changes seen in airway resistance with changes in lung volume ${ }^{17}$-and also increases with methacholine challenge. ${ }^{18-20}$ Both pulmonary tissue and chest wall resistance show changes with age. ${ }^{21} 22$

\section{CLINICAL USE OF THE INTERRUPTER TECHNIQUE}

Despite these reservations, measurement of Rint by the interrupter technique, if used carefully, does have a place in the measurement of lung function clinically in young children.

Commercially available equipment allows the measurement of Rint at peak tidal flow or at set flows during either inspiration or expiration. This equipment includes a rapidly closing valve that occludes the airway for $100 \mathrm{~ms}$ before allowing normal respiration to resume. There is no simple answer to the most correct or reliable protocol. Airway resistance is dependent on the lung volume at which it is measured, increasing with decreasing lung volume. Rint is also flow dependent, increasing with increasing flow. There are expected physiological variations between inspiration and expiration, with airway resistance being lower during inspiration due to the airway being "pulled open" by the forces of interdependence. In practice, neither flow nor volume dependence of resistance have been found to be important effects during the tidal volume range. ${ }^{23-25}$ What is more important is to ensure an adequate signal to noise ratio and reproducible data. For practical purposes, most investigators appear to be adopting the practice of measuring Rint during the expiratory phase of respiration at peak tidal flow, which hopefully coincides with the mid tidal volume range. ${ }^{5623}$

Both of the recent papers published in Thorax $^{56}$ deal with the repeatability of Rint measurements. Repeatability is a crucial issue for the use of a lung function test. The interrupter technique has been shown to have a good short term repeatability (over a time span of minutes) in preschool children. ${ }^{23} 2627$ Rint repeatability has also been shown to be age dependent, with younger children having higher variability between measurements. ${ }^{27}{ }^{28}$ Both Chan et $a l^{5}$ and Beelen et $a l^{6}$ reported good short term repeatability. They also evaluated long term repeatability (over a time span of weeks) and found good long term repeatability, which was similar in the two papers, in children with no history of respiratory symptoms ${ }^{5}$ and in a sample of the general population, ${ }^{6}$ confirming the findings previously reported in clinically stable preschool children with a history of either cough or wheeze. ${ }^{23}$ However, greater long term variability between measurements was found in children with persistent cough or previous wheeze, ${ }^{5}$ which suggests that the lower long term repeatability in symptomatic children might be due to the variability of the disease rather than the variability of the technique.

Many other technical issues also need to be considered, including (1) what constitutes an acceptable measurement; (2) how should the post-occlusion mouth pressure be calculated; and (3) whether the mean or median of a series of measurements should be reported. Each single interruption should be considered acceptable when the trace of mouth pressure versus time has the correct shape. A trace from an occlusion made during expiration in which mouth pressure decreases or stays flat after the initial rapid change suggests air leakage around the mouthpiece or an altered ventilatory pattern ${ }^{27} 29$ and should be discarded. Pressure-time traces obtained when the child was breathing irregularly, had the neck hyperextended or flexed, or was speaking or moving his/her tongue should also be discarded. Several algorithms for calculating mouth pressure during airflow interruption have been proposed. Four main models have so far been used: curvilinear back extrapolation $\left(\right.$ Rint $\left._{C}\right)$, two-point linear back extrapolation ( Rint $_{\mathrm{L}}$, usually from 70 and $30 \mathrm{~ms}$ to 15 or $0 \mathrm{~ms}$ after interruption), end oscillatory pressure ( Rint $\left._{\mathrm{EO}}\right)$, and end interruption pressure $\left(\right.$ Rint $\left._{\mathrm{FI}}\right)$. The Rint values obtained with these algorithms have been compared with airway resistance obtained with body plethysmography (Raw) in a study by Phagoo et al in healthy adults. ${ }^{30}$ Rint $_{C}$ values were similar to Raw, while Rint values calculated with the other three algorithms were significantly higher. Another study in healthy adults showed that Rint ${ }_{\mathrm{FI}}$ and Rint $_{\mathrm{L}}$ were more sensitive than Rint ${ }_{C}$ in detecting airway calibre change during methacholine challenge testing. ${ }^{31}$ Until more studies show which algorithm is most sensitive in detecting bronchial obstruction in clinical practice, it has been proposed that the linear back extrapolation should be used for Rint calculation. ${ }^{32}$ A recent paper has shown that mean and median Rint values are not significantly different. ${ }^{33}$ However, since the Rint values obtained during a measurement session are not normally distributed, it was also suggested that median values should be used as they are theoretically more correct. ${ }^{29}$ What is critical is for investigators to report accurately their measurement conditions-including the triggering conditions for Rint measurements-to ensure that readers are able to compare "like with like". 


\section{CONCLUSIONS}

Measurement of Rint is a technique that shows considerable promise for assessing lung function in children of preschool age. However, proper attention must be paid to the assumptions that underlie the technique, and appropriate consideration of the effect of the measurement conditions on these assumptions is important for producing reliable data. From the studies reported to date, one has confidence that Rint can be used clinically to follow changes in lung function with growth and development, be used to manage lung disease in young children, and to measure acute response to bronchodilators. The use of Rint as the primary outcome for challenge tests such as methacholine requires further study, and whether Rint proves to be more or less useful than other measurements of lung function currently being investigated in preschool children, such as the forced oscillation technique and spirometry, remains to be seen. However, for Rint to be a useful measurement, standard procedures must be developed for performing the measurement and for reporting the results, and these standards must be adhered to.

Thorax 2003;58:742-744

\section{Authors' affiliations}

P D Sly, TVW Telethon Institute for Child Health Research and Centre for Child Health Research, University of Western Australia, Perth, Australia E Lombardi, Paediatric Allergy and

Pulmonology Centre, "Anna Meyer" Children's Hospital, Department of Paediatrics, University of Florence, 50132 Florence, Italy

Correspondence to: Professor P D Sly, TVW Telethon Institute for Child Health Research and Centre for Child Health Research, University of Western Australia, Perth, Australia;

peters@ichr.uwa.edu.au

\section{REFERENCES}

1 Eigen H., Bieler H, Grant D, et al. Spirometric pulmonary function in healthy preschool children. Am J Respir Crit Care Med 2001;163:619-23.
2 Beydon N, Amsallem F, Bellet $M$, et al. Pulmonary function tests in preschool children with cystic fibrosis. Am J Respir Crit Care Med 2003;166: 1099-104.

3 Pao CS, McKenzie SA. Randomized controlled trial of fluticasone in preschool children with intermittent wheeze. Am J Respir Crit Care Med 2003;166:945-9

4 Marostica PJC, Weist AD, Eigen $\mathrm{H}$, et al. Spirometry in 3- to 6-year-old children with cystic fibrosis. Am J Respir Crit Care Med 2003;166:67-71

5 Chan EY, Bridge PD, Dundas I, et al. Repeatability of airway resistance measurements made using the interrupter technique. Thorax 2003;58:344-7.

6 Beelen RMJ, Smit HA, van Strien RT, et al. Short and long term variability of the interrupter technique under field and standardised conditions in 3-6 year old children. Thorax 2003;58:761-4.

7 Neergaard KV, Wirz K. Die messung der stromungswiderstande in den atemwegen des menschen, insbesondere bei asthma und emphysema. Z Klin Med 1927; 105:51-82.

8 Otis AB, Proctor DF. Measurement of alveolar pressure in human subjects. Am J Physiol 1948;152:106-12.

9 Mead J, Whittenberger JL. Evaluation of airway interruption technique as a method of measuring pulmonary air-flow resistance. $J$ Appl Physiol 1954;6:408-16.

10 Marshall R, duBois $A B$. The measurement of the viscous resistance of the lung tissues in normal man. Clin Sci 1956;15:161-70.

11 Bates JHT, Baconnier P, Milic-Emili J. A Theoretical analysis of interrupter technique for measuring respiratory mechanics. J Appl Physiol 1988;64:2204-14

12 Bates JHT, Ludwig MS, Sly PD, et al. Interrupter resistance elucidated by alveolar pressure measurement in open-chest normal dogs. J Appl Physiol 1988;65:408-14.

13 Ludwig MS, Romero PV, Sly PD, et al. Interpretation of the interrupter resistance after histamine-induced constriction in the dog. $J$ Appl Physiol 1990;68: 1651-6.

14 Bates JHT, Sly PD, Kochi T, et al. The effect of proximal compliance on interrupter measurement of resistance. Respir Physiol 1987;70:301-12.

15 Bates JHT, Hunter IW, Sly PD, et al. Effect of the valve closure time on the determination of respiratory resistance by flow interruption. Med Biol Eng Comput 1987;25:136-40.

16 Sly PD, Bates JHT. Computer analysis of physical factors affecting the use of the interrupter technique in infants. Pediatr Pulmonol 1988;4:219-24.

17 Petak F, Hayden M, Hantos Z, et al. Volume dependence of respiratory impedance in infants. Am J Respir Crit Care Med 1997; 156:1 172-7.

18 Sly PD, Lanteri CJ. Partitioning of pulmonary responses to inhaled methacholine in puppies. J Appl Physiol 1991;71:886-91.
19 Hayden MJ, Petak F, Hantos Z, et al. Using low frequency oscillation to detect bronchodilator responsiveness in infants. Am J Respir Crit Care Med 1998;157:574-9.

20 Hall GL, Hantos Z, Wildhaber JH, et al. Methacholine responsiveness in infants assessed with low frequency forced oscillation and forced expiration techniques. Thorax 2001;56:42-7.

21 Lanteri CJ, Sly PD. Changes in respiratory mechanics with age. J Appl Physiol 1993;74:369-78.

22 Hall GL, Hantos Z, Petak F, et al. Airway and respiratory tissue mechanics in normal infants. Am J Respir Crit Care Med 2000; 162: 1397-402.

23 Lombardi E, Sly PD, Concutelli G, et al. Reference values of interrupter respiratory resistance in healthy preschool white children Thorax 2001;56:691-5.

24 Lanteri CJ, Kano S, Nicolai T, et al. Measurement of dynamic respiratory mechanics in the neonatal and pediatric intensive care: the multiple linear regression technique. Pediatr Pulmonol 1995; 19:29-45.

25 Kano S, Lanteri CJ, Duncan AW, et al. The influence of non-linearities on estimates of respiratory mechanics using multi-linear regression. J Appl Physiol 1994;77: 1 185-97

26 Oswald-Mammosser M, Llerena C, Speich $J P$, et al. Measurements of respiratory resistance by the interrupter technique in healthy and asthmatic children. Pediatr Pulmonol 1997;24:78-85.

27 Bridge PD, Ranganathan S, McKenzie SA. Measurement of airway resistance using the interrupter technique in preschool children in the ambulatory setting. Eur Respir $J$ 1999;13:792-6.

28 Arets HGM, Brackel HJL, van der Ent CK. Applicability of interrupter resistance measurements using the MicroRint in daily practice. Respir Med 2003;97:366-74.

29 Merkus PJFM, Mijnsbergen JY, Hop WCJ, et al. Interrupter resistance in preschool children measurement characteristics and reference values. Am J Respir Crit Care Med 2001;163:1350-5.

30 Phagoo SB, Watson RA, Pride NB, et al. Accuracy and sensitivity of the interrupter technique for measuring the response to bronchial challenge in normal subjects. Eur Respir J 1993;6:996-1003.

31 Phagoo SB, Watson RA, Silverman M, et al. Comparison of four methods of assessing airflow resistance before and after induced airway narrowing in normal subjects. J Appl Physiol 1995;79:518-25

32 Carter ER. It is time to consider standardizing the interrupter technique. Eur Respir J 1997; 10:1428-9.

33 Bridge PD, McKenzie SA. Airway resistance measured by the interrupter technique: expiration or inspiration, mean or median? Eur Respir J 2001;17:495-8. 